\title{
Development and Initial Validation of Micromanagement Scale for School Principals
}

\author{
İbrahim Limon* \\ Ministry of National Education, Sakarya, Turkey, ORCID: 0000-0002-5830-7561 \\ Ümit Dilekçi \\ Department of Child Development, Batman University, Batman, Turkey
} ORCID: 0000-0002-6205-1247

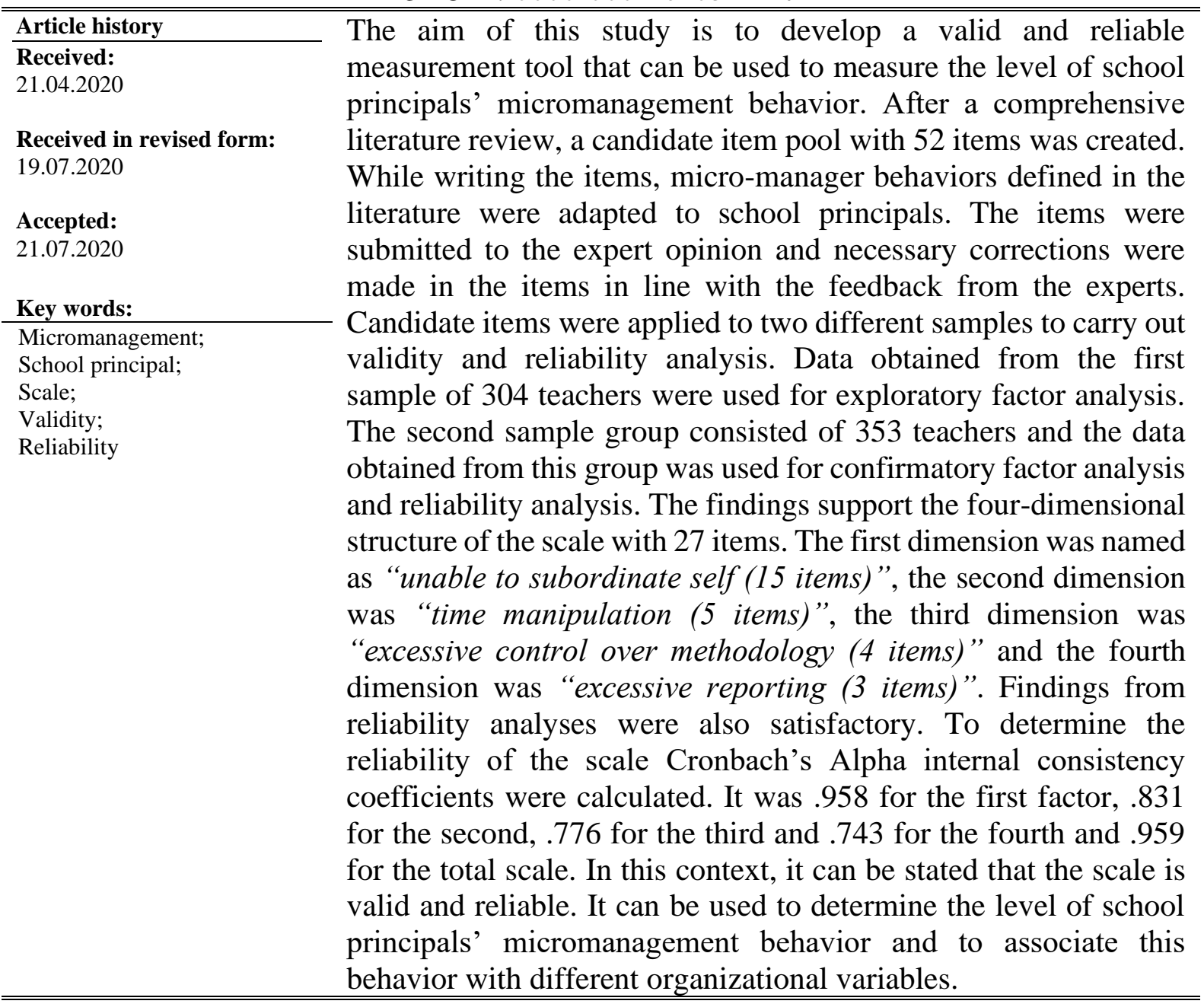

*Correspondency: ibomon@gmail.com 


\section{Introduction}

"Surround yourself with the best people you can find, delegate authority, and don't interfere as long as the policy you've decided upon is being carried out."

Ronald Reagan

The most important asset of organizations is their human resources. Management refers to the whole process of organizing, coordinating, managing and evaluating this human resource with material resources to achieve the objectives of the organization (Balc1, 2019). As stated in the definition, the main role of the managers is to use the material and human resources of the organization in the most efficient way for organizational purposes (Bursalıoğlu, 2010). In this context, managers exhibit different management styles for employees to be more productive, to cooperate more around organizational goals and to work more effectively. However, these management styles exhibited by managers can sometimes contain risks (Bielaszka-DuVernay, 2008). Micromanagement, which has recently been subject to different researches (Chambers, 2004; Hume, 2019; Lewis, 2014; White, 2010; Wright, 2000 etc.), can be considered as one of these methods.

In Oxford Learner's Dictionaries, micromanagement is defined as controlling every detail in a project or event, especially regarding the task that employees carry out. On the other hand, in organizational literature, various definitions of the term are available (Chambers, 2004; Clearly, Hungerford, Lopez \& Cutcliffe, 2015; Lewis, 2014; Sidhu, 2012; Wright, 2000). It is to manage closely, evaluate in detail and manage a small part of a very comprehensive process (Wright, 2000); excessive, unwanted, counter-productive intervention or disruption of the flow (Chambers, 2004) or the control of managers for insignificant details about daily activities on employees, teams and the organization (Clearly et.al., 2015). According to Lewis (2014), micromanagement is a management style in which administrators are excessively interested in minor details about the tasks executed by the subordinates and restricts their creativity. Sidhu (2012) states that micromanagement creates a feeling in employees that all their activities are monitored by the manager and it can be associated with excessive attention to detail, planning tasks to the smallest detail, monitoring employees' rest or working hours obsessively. Although these may seem like the behaviors that any manager should do, they have some problems and cause the manager to miss the big picture. On the other hand, Chambers (2004) states that micromanagement is not abusive management and behaviors such as temper tantrums, ridicule, public embarrassment, talking people's behind, inappropriate language, purposeful untruths and disrespect, prejudice, trick, biased performance evaluation and demand of unquestioning loyalty are characteristics of abusers, not micromanagers.

Micromanagers make a false assumption that they can carry out the organization's key functions on their own. Such an assumption may be valid for the period when the organization was first established. However, as new employees join the organization and subordinate-superior relationships emerge in the process, the manager's task is to clearly define previously successful procedures and rely on subordinates by assigning specific tasks to them (Alizor, 2013). As a matter of fact, as Chambers (2004) stated, the persistence of managers in micromanagement may bring some problems for the organization, employees and even managers. In this context, Delgado, Strauss \& Ortega (2015) argue that micromanagement can damage the organization's capacity to innovate and create value-added services. According to Chambers (2004), retention problems, increase in organizational conflicts, late arrivals and absenteeism, the search for the 
right of employees through law and complaints, decrease in quality and deterioration in the processes and inadequacy in making up for deficiencies are among organizational-level problems caused by micromanagement. As for employee level problems, a decrease in creativity, productivity, performance and employee morale and increase in intention to quit can be listed (Chambers, 2004; Clearly et.al., 2015; Collins \& Collins, 2002; Lewis, 2014; Wright, 2000). In case of a crisis, employees may not volunteer to sacrifice their own time or resources to address the problem, considering that the manager will take full responsibility and praise in managing through crisis (Delgado et al., 2015). In addition to these, employees may avoid risk taking, experience lower level of job satisfaction and commitment, feel worthless, resentment or frustration (Chambers, 2004). When all decisions are taken by managers, employees may think that they are not important and not trusted (Plemons, 2014; Sledge, 2016). While the manager has a perception that the employees are not capable of completing any task or function, they may be disappointed that they cannot incorporate their own ideas into the process (Delgado et al., 2015). In this context, micromanagement can be considered as a management style that restricts the effectiveness and efficiency of employees (Serrat, 2010). Lastly, as stated above micromanaging may bring about some problems for those who is practicing it, namely micromanagers. These are burnout (Collins \& Collins, 2002), the illusion of effectiveness (Delgado et al., 2015), not being able to find solutions quickly to problems, becoming a bottleneck, creating an obstacle for change, not being able to find support within the organization (Chambers, 2004). As can be seen, micromanagement can negatively affect not only those who are exposed to this management style but also the organization and even the manager himself.

As stated above, micromanagement, a kind of bullying as stated by Serrat (2011), is an unfortunate event both for organization and its stakeholders. For this reason, its prevention is of great importance. Wright (2000) proposes four strategies to managers to eliminate micromanagement. The first one is flexibility, which refers to the ability to implement different management strategies for different employees. The second is to identify specific, measurable, achievable, realistic goals for employees and to set these goals with appropriate timing. The third is to give employees autonomy over method as long as it is ethical to achieve the desired results. The last strategy is to coach the subordinates. On the other hand, Collins \& Collins (2002) argue that proper delegation of tasks, creating a vision for the future, hiring employees with appropriate skills, having a manual of organizational principles and procedures, determining the boundaries in subordinate-superior relationships, tolerating employees' mistakes can also be helpful in minimizing incidents of micromanagement. White (2010) lists the issues to be considered for the prevention of micromanagement as follows:

- The fact that any employee is doing his job well may not mean that he will be a good manager. Therefore, careful selection of those to be brought to the management position.

- Ensuring that all employees understand clearly what is expected from them.

- Encouraging managers to delegate authority.

- Creating an organizational environment open to innovation and original ideas by tolerating mistakes.

- Minimizing the hierarchy (horizontal organization as much as possible).

- Promoting leadership practices.

Chambers (2004) states that micromanagement is a very subjective concept. As a matter of fact, one can perceive a situation as support or interaction while another perceives it as an intervention. Situations that are perceived as guiding and collaboration by a person can be seen 
as manipulation, excessive control or interference by another one. However, White (2010) proposes some criteria to understand whether there is micromanagement in organizations or not. In this sense, we can ask the following questions:

- Are decisions made by employees with competence, skills, and knowledge in making decisions?

- Are talented employees empowered? Are they allowed to make decisions? Are they responsible for performance?

- Is the turnover rate high?

- Are there managers in the organization who take responsibility for most of the tasks and make too many decisions?

In organizations, there are some factors that may contribute to micromanagement. According to Serrat (2010) and White (2010) organizational structure, especially with many hierarchical levels, are amongst these factors. Because, in such organizational structures, the lower level managers do not have much authority to make decisions; so, they can fill this gap by applying micromanagement to their subordinates. Chambers (2004), on the other hand, suggests that micromanagement can result from organizational culture and individual style. According to this perspective, micromanagement can become an organizational norm when the top managers behave in this way. Another factor is inadequate training on leadership. On the other hand, individuals can show micromanagement tendency regardless of organizational culture. There may be individuals who exhibit micromanagement especially in environments where cooperation and interaction are high. This may be due to the individual's personal preference or lack of awareness and training. Lewis (2014) briefly explains some other reasons for the adoption of micromanagement as follows:

- Learning such management style from past managers.

- Fear of being blamed for failure.

- Comfort offered by controlling the power.

- When there is a confusion about the priorities and goals in the organization and the goals are not clearly defined and shared with the employees, micromanagers step in and fill the hole.

- Subordinates and superiors are in the same physical environment.

- Lack of trust.

As mentioned above, micromanagement has some adverse effects on organizations, employees and managers. However, it is not a one-sided evil. There are some situations where it can be employed with positive outcomes only in the short term (Lewis, 2014; Sidhu, 2012; White, 2010). For example, it can be used when training newcomers in the organization, increasing the effectiveness of employees who cannot perform at the desired level, managing high-risk situations, and when there is no one to take responsibility for any task (Collins \& Collins, 2002). It can also be applied for projects which deteriorates considering the stress level employees can endure or where all other methods fail (Sidhu, 2012). Bergstrom \& Raknes (2016) suggest that micromanagement can be sector-specific style for retail organizations. It can contribute to effectiveness in these organizations because it is a sector with high employee turnover; and employees are young and inexperienced with low job motivation. Micromanagement may be helpful to overcome problems arising from these features in retail organizations.

Micromanagement is also addressed in the context of schools (Lampton, 2002; Meyers \& Richardson, 2014; Saenz, 2005; Villarreal, 2003). Schools, with a bureaucratic organizational 
structure, have intense formal relations and rules which paves the way for an approach to control employees closely (Küçükçayır \& Güçlü, 2017; Yılmaz \& Beycioğlu, 2017). As a matter of fact, findings in literature reveal the existence of micromanagement and its adverse effects in schools. Villarreal (2003) states that micromanagement is among the most important factors in schools that damage relations among stakeholders, destroy the trust and employees' ability to do business. On the other hand, Scott (2010) examined the relationship between teacher retention and micromanagement. The findings showed that participants being micromanaged tended to quit teaching. Kaskey (2015) found that school principals being micromanaged left their duties. Shortly, it can be said that micromanagement has the potential to bring about some problems at both organizational and individual levels in schools just like others.

\section{Significance of the study}

Micromanagement attracts a growing interest in international literature. However, there is a gap in the literature regarding schools. In terms of national literature, micromanagement stands as a field of study waiting to be discovered. In this context, it is anticipated that the current study will contribute to both national and international literature. This study will introduce the concept of micromanagement to the national literature, present a conceptual framework and serve as a guide for further research. Additionally, it is anticipated that the scale developed within the scope of the current study will be used to determine the prevalence of micromanagement behaviors in schools. Findings obtained through this scale may have some implications both for policy makers and educational administrators.

\section{Research Objective}

The aim of this study is to develop a valid and reliable measurement tool that can be used to determine the level of school principals' micromanagement behaviors based on teachers' perceptions. In this sense, this is a two-phase study. In the first phase, the factorial structure through exploratory factor and confirmatory factor analysis were assessed. In the second phase, the reliability of the scale was checked.

\section{Method}

\section{Research Model}

This is a scale development and validation study. The procedures followed in line with this aim is based on DeVellis (2017). The steps can be summarized as follows:

- Determining the behavior to be measured.

- Creating of a candidate item pool.

- Deciding on measurement format.

- Getting expert opinion.

- Considering additional validation items.

- Implementation of the scale.

- Evaluation of the items.

- Optimization of scale length. 


\section{Participants}

This study was conducted on two different study groups. Data obtained from the first study group was used to conduct exploratory factor analysis and data from the second study group was used for confirmatory factor analysis. Table 1 provides information on the demographics of the participants in both study groups.

Table 1. Demographics of participants

\begin{tabular}{|c|c|c|c|c|c|c|c|}
\hline \multicolumn{4}{|c|}{ Exploratory factor analysis (1. Group) } & \multicolumn{4}{|c|}{ Confirmatory factor analysis (2. Group) } \\
\hline Variable & Group & $\mathbf{n}$ & $\%$ & Variable & Group & n & $\%$ \\
\hline \multirow{2}{*}{ Gender } & Female & 163 & 53.6 & \multirow{2}{*}{ Gender } & Female & 194 & 55 \\
\hline & Male & 141 & 46.4 & & Male & 159 & 45 \\
\hline \multirow{5}{*}{ Grade level } & Pre-school & 22 & 7.2 & \multirow{5}{*}{ Grade level } & Pre-school & 13 & 3.7 \\
\hline & Primary & 62 & 20.4 & & Primary & 79 & 22.4 \\
\hline & Secondary & 93 & 30.6 & & Secondary & 209 & 59.2 \\
\hline & High school & 114 & 37.5 & & High school & 47 & 13.3 \\
\hline & Other (PTC etc.) & 13 & 4.3 & & Other (PTC etc.) & 5 & 1.4 \\
\hline \multirow{5}{*}{ Experience } & $0-5$ & 33 & 10.9 & \multirow{5}{*}{ Experience } & $0-5$ & 62 & 17.6 \\
\hline & $6-10$ & 61 & 20.1 & & $6-10$ & 69 & 19.5 \\
\hline & $11-15$ & 77 & 25.3 & & $11-15$ & 96 & 27.2 \\
\hline & $16-20$ & 75 & 24.7 & & $16-20$ & 64 & 18.1 \\
\hline & $21 \geq$ & 58 & 19.1 & & $21 \geq$ & 62 & 17.6 \\
\hline \multirow[t]{3}{*}{ School type } & Public & 287 & 94.4 & \multirow[t]{2}{*}{ School type } & Public & 339 & 96 \\
\hline & Private & 17 & 5.6 & & Private & 14 & 4 \\
\hline & Total & 304 & 100 & & Total & 353 & 100 \\
\hline
\end{tabular}

As Table 1 shows, there are 304 participants in the first study group (EFA). Of the participants in this group, 163 are women (53.6\%) and 141 are men (46.4\%); 22 of them work in nursery schools $(7.2 \%), 62$ in primary schools $(20.4 \%), 93$ in secondary schools (30.6\%), 114 in high schools $(37.5 \%), 13$ in other educational institutions (4.3\%). 33 participants have an experience of 0-5 years (10.9\%), 61 participants 6-10 years $(20.1 \%)$, 77 participants $11-15$ years $(25.3 \%)$, 75 participants 16-20 years (24.7\%) and 58 participants 21 years and over (19.1\%). 287 of the participants work in public schools $(94.4 \%)$ and 17 (5.6\%) in private schools.

In the second study group (CFA), there are 353 participants. Of the participants 194 are women (55\%) and 159 are men (45\%). 13 work in nursery schools (17\%), 79 in primary schools (22.4\%), 209 in secondary schools (59.2\%), 47 in high schools (13.3\%), and 5 in other educational institutions (1.4\%). 62 participants (17.6\%) have an experience of 0-5 years, 69 participants (19.5\%) 6-10 years, 96 participants (27.2\%) 11-15 years, 64 participants $(18.1 \%)$ 16-20 years and 62 participants (17.6\%) 21 years and over. 339 of the participants (96\%) work in public schools and $14(4 \%)$ in private schools.

\section{Creation of the Candidate Item Pool}

A comprehensive literature review was carried out during the creation of the candidate item pool. A total of 52 micromanagement indicators were determined based on the literature and existing scale items (Chambers, 2004; Clearly et.al., 2015; Fracaro, 2007; Jazzar, 2005; Hills, 2017; Hume, 2019; Li \& Khalid, 2015; Mingus \& Jing, 2017 cited in Hume, 2019; Prosper, 2012; Schuster, 2019; Sulphey \& Upadhyay, 2019; White, 2010; Wright, 2000). These indicators are presented in Table 2 below. 
Table 2. Indicators of micromanagement

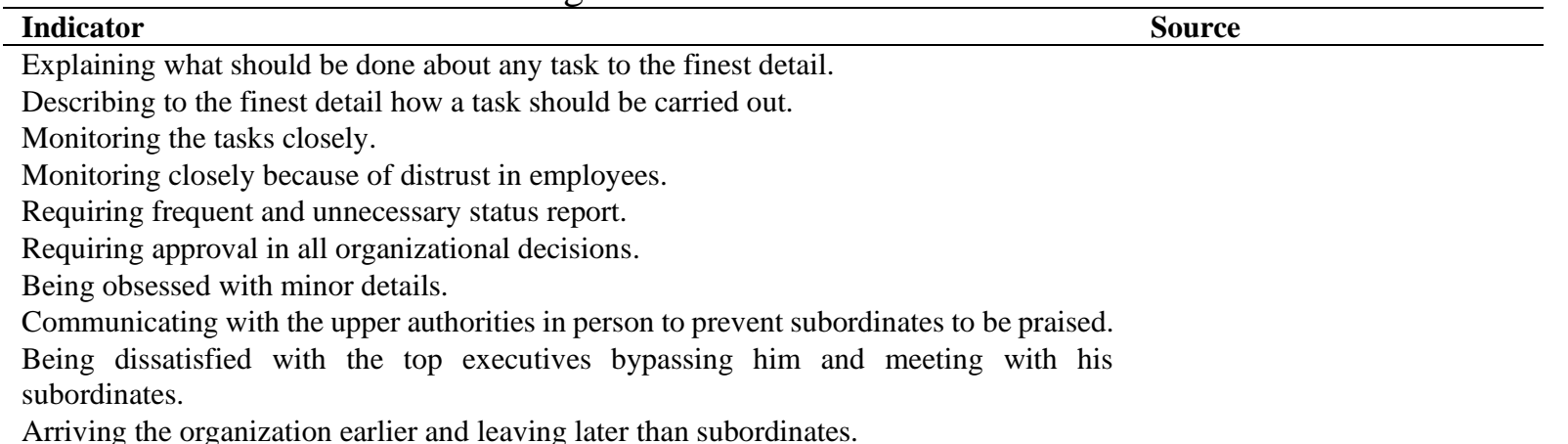

Arriving the organization earlier and leaving later than subordinates.

Calling the office frequently while on vacation.

Arriving late for meetings because of busyness.

White, 2010

Focusing on the result instead of encouraging creativity in projects or activities.

Being too busy to meet the subordinates.

Getting involved in every organizational activity.

Intolerance to mistakes.

Praising the subordinates very seldom.

Considering the subordinates incompetent.

Blaming the subordinates hurriedly but not accepting his/ her own mistakes.

Trying to do many things simultaneously so not focusing any of them enough.

Monitoring not only the ones not working efficiently but also the ones working efficiently.

Avoid taking responsibility and seeking scapegoats for own faults.

Considering that many tasks are too difficult / complex to be delegated to subordinates.

Avoiding working with more competent or experienced subordinates.

Avoiding giving or accepting feedback.

Fracaro, 2007

Changing his/her mind frequently.

Requiring papers before deadlines.

Putting deadlines for papers without priority.

Clearly et.al., 2015

Considering all the options again and again before making decisions.

Postponing the paperwork signatures wanting them to be perfect or because of indecisiveness.

Jazzar, 2005

The effort to have own opinions/wishes accepted by using authority.

Requesting approval of each decision taken and every activity carried out.

Inability to delegate authority.

Over precision about timing.

Avoiding going on leave with the fear of things would go wrong in his/her absence.

Chambers, 2004

Reminding something about duties at every encounter with subordinates.

No listening to subordinates because of thinking that s/he knows everything.

Avoiding compromise in case of a conflict considering it as a weakness.

Arranging last minute meetings frequently.

Satisfaction with always being approved.

Considering that things go smoothly because s/he is in control.

Considering that the subordinates should be directed because they are incompetent.

Assigning tasks interfering with daily routine.

Prioritizing own experiences.

Considering that $\mathrm{s} / \mathrm{he}$ is the most important person in the organization.

Checking the things if they are done by methods dictated by her/him.

Having the worry that the subordinates will leave her/him in the background.

Feeling dissatisfied with acting without consulting her/him.

Making the subordinates feel that they are always being monitored.

Monitoring even the routine activities constantly.

Requiring knowing the details that will not affect the quality of tasks carried out.

Setting rules not contributing to organizational effectiveness.

Wright, 2000

Prosper, 2012

Schuster, 2019

Li \& Khalid, 2015

Sulphey \& Upadhyay, 2019

Hills, 2017

Hume, 2019

Mingus \& Jing, 2017

While the indicators presented in Table 2 were being turned into scale items, adaptations were made for educational organizations. On writing the candidate items, a panel of 10 experts evaluated them in terms of clarity, expressions, grammar etc. (8 of them had a Phd degree and 2 had an MA degree). 6 of the experts were in the field of educational management; one in the field of measurement and evaluation, and the other in education programs. The other two 
experts with MA degrees work as teachers in the fields of Turkish and English language teaching. Items were revised based on the feedback from the experts. They were 5-point Likert type ones, ranging from (1) Strongly Disagree to (5) Strongly Agree.

\section{Data Analysis}

IBM Statistics SPSS (25) and IBM SPSS AMOS (23) programs were used in data analysis. First, exploratory and confirmatory factor analyzes were performed to determine the factor structure of the scale (Huck, 2012; Worthington \& Whittaker, 2006). Then, reliability analyzes of the scale were carried out.

\section{Findings}

\section{Findings on construct validity}

\section{Findings on exploratory factor analysis}

Firstly, correlation matrix, KMO value and Bartlett sphericity test were taken into consideration to evaluate the suitability of the data set for factor analysis (Field, 2009). Although there are no limits on what is too high or too low, the correlations should be statistically significant in correlation matrix (Hair, Black, Babin \& Anderson, 2014). As can be seen in Table 3 below, all the correlations between the variables are significant at $p<.001$. On the other hand, the KMO value was .952 and the Bartlett sphericity test was significant $\left(\chi^{2}=5844.149, \mathrm{df}=351 ; p=.000\right)$. Thusly, it can be said that the data set was suitable for factor analysis (Pallant, 2007). 
Table 3. Correlation matrix*

\begin{tabular}{|c|c|c|c|c|c|c|c|c|c|c|c|c|c|c|c|c|c|c|c|c|c|c|c|c|c|c|c|}
\hline Item & 3 & 5 & 7 & 8 & 17 & 18 & 19 & 22 & 25 & 26 & 28 & 29 & 34 & 37 & 38 & 39 & 40 & 41 & 42 & 43 & 44 & 46 & 47 & 48 & 49 & 50 & 52 \\
\hline 3 & 1.00 & & & & & & & & & & & & & & & & & & & & & & & & & & \\
\hline 5 & .350 & 1.00 & & & & & & & & & & & & & & & & & & & & & & & & & \\
\hline 7 & .528 & .453 & 1.00 & & & & & & & & & & & & & & & & & & & & & & & & \\
\hline 8 & .432 & .435 & .667 & 1.00 & & & & & & & & & & & & & & & & & & & & & & & \\
\hline 17 & .406 & .269 & .502 & .474 & 1.00 & & & & & & & & & & & & & & & & & & & & & & \\
\hline 18 & .299 & .215 & .412 & .339 & .508 & 1.00 & & & & & & & & & & & & & & & & & & & & & \\
\hline 19 & .264 & .192 & .361 & .345 & .433 & .521 & 1.00 & & & & & & & & & & & & & & & & & & & & \\
\hline 22 & .324 & .231 & .342 & .261 & .237 & .091 & .242 & 1.00 & & & & & & & & & & & & & & & & & & & \\
\hline 25 & .290 & .194 & .306 & .335 & .369 & .157 & .293 & .542 & 1.00 & & & & & & & & & & & & & & & & & & \\
\hline 26 & .365 & .323 & .370 & .354 & .414 & .182 & .395 & .584 & .555 & 1.00 & & & & & & & & & & & & & & & & & \\
\hline 28 & .270 & .201 & .274 & .292 & .376 & .248 & .317 & .309 & .416 & .392 & 1.00 & & & & & & & & & & & & & & & & \\
\hline 29 & .300 & .200 & .303 & .307 & .325 & .212 & .330 & .473 & .513 & .535 & .658 & 1.00 & & & & & & & & & & & & & & & \\
\hline 34 & .284 & .363 & .435 & .348 & .389 & .211 & .277 & .359 & .500 & .498 & .324 & .383 & 1.00 & & & & & & & & & & & & & & \\
\hline 37 & .423 & .480 & .554 & .520 & .451 & .277 & .382 & .387 & .429 & .528 & .294 & .419 & .545 & 1.00 & & & & & & & & & & & & & \\
\hline 38 & .355 & .391 & .446 & .467 & .405 & .210 & .366 & .355 & .516 & .596 & .321 & .475 & .575 & .723 & 1.00 & & & & & & & & & & & & \\
\hline 39 & .339 & .327 & .417 & .335 & .332 & .211 & .328 & .360 & .389 & .501 & .374 & .437 & .448 & .617 & .671 & 1.00 & & & & & & & & & & & \\
\hline 40 & .367 & .462 & .520 & .469 & .410 & .286 & .409 & .394 & .462 & .547 & .319 & .448 & .620 & .754 & .707 & .664 & 1.00 & & & & & & & & & & \\
\hline 41 & .305 & .432 & .501 & .450 & .393 & .230 & .366 & .407 & .383 & .503 & .340 & .427 & .531 & .705 & .623 & .591 & .748 & 1.00 & & & & & & & & & \\
\hline 42 & .306 & .397 & .514 & .391 & .394 & .268 & .354 & .385 & .420 & .534 & .272 & .398 & .582 & .698 & .625 & .584 & .728 & .771 & 1.00 & & & & & & & & \\
\hline 43 & .407 & .503 & .505 & .473 & .414 & .214 & .366 & .393 & .458 & .563 & .292 & .420 & .596 & .748 & .701 & .633 & .810 & .733 & .758 & 1.00 & & & & & & & \\
\hline 44 & .347 & .440 & .490 & .435 & .357 & .241 & .359 & .378 & .467 & .527 & .242 & .386 & .591 & .743 & .625 & .571 & .758 & .720 & .770 & .790 & 1.00 & & & & & & \\
\hline 46 & .278 & .388 & .426 & .390 & .362 & .237 & .290 & .323 & .342 & .455 & .257 & .371 & .473 & .640 & .537 & .519 & .604 & .623 & .619 & .640 & .633 & 1.00 & & & & & \\
\hline 47 & .334 & .452 & .514 & .404 & .386 & .296 & .390 & .356 & .422 & .518 & .333 & .424 & .548 & .709 & .602 & .548 & .761 & .736 & .738 & .710 & .760 & .696 & 1.00 & & & & \\
\hline 48 & .302 & .340 & .430 & .334 & .402 & .184 & .278 & .344 & .455 & .478 & .289 & .411 & .609 & .574 & .599 & .513 & .662 & .670 & .688 & .687 & .696 & .561 & .659 & 1.00 & & & \\
\hline 49 & .298 & .326 & .440 & .347 & .380 & .185 & .349 & .439 & .469 & .571 & .305 & .497 & .604 & .656 & .664 & .588 & .686 & .610 & .629 & .681 & .686 & .559 & .632 & .685 & 1.00 & & \\
\hline 50 & .333 & .366 & .463 & .356 & .353 & .420 & .350 & .251 & .306 & .363 & .279 & .291 & .393 & .525 & .421 & .457 & .516 & .514 & .493 & .479 & .511 & .522 & .583 & .487 & .485 & 1.00 & \\
\hline 52 & .245 & .344 & .472 & .363 & .362 & .270 & .389 & .316 & .348 & .456 & .275 & .358 & .510 & .585 & .671 & .531 & .563 & .652 & .663 & .565 & .604 & .526 & .589 & .521 & .531 & .620 & 1.00 \\
\hline
\end{tabular}

"All correlations are significant at $p<.001$ 
After deciding the suitability of the data set for factor analysis, it was aimed to determine the factor structure of the scale. Exploratory factor analysis was conducted using varimax method. Determining the number of useful factors, Kaiser criterion and scree plot were taken into consideration. The first analysis was conducted without restricting the number of factors and seven factors emerged with an eigenvalue greater than 1.0. However, checking the scree plot and taking into consideration the interpretability of factors (SSencan, 2005) the analysis was re-run by restricting the factor numbers to four. The evaluation of the findings revealed that this four-factor structure with 27 items satisfied the cutoff values in literature.

Table 4. Communalities and rotated factor loadings of items

\begin{tabular}{|c|c|c|c|c|c|c|}
\hline Item no & Communalities & Item no & Factor 1 & Factor 2 & Factor 3 & Factor 4 \\
\hline 3 & .600 & 44 & .826 & .182 & .232 & - \\
\hline 5 & .532 & 42 & .819 & .183 & .172 & .151 \\
\hline 7 & .717 & 47 & .793 & .176 & .195 & .214 \\
\hline 8 & .661 & 43 & .793 & .240 & .322 & - \\
\hline 17 & .579 & 41 & .791 & .200 & .203 & .156 \\
\hline 18 & .752 & 40 & .787 & .252 & .266 & .144 \\
\hline 19 & .600 & 48 & .749 & .260 & .116 & - \\
\hline 22 & .576 & 37 & .732 & .211 & .375 & .147 \\
\hline 25 & .618 & 49 & .717 & .380 & .111 & - \\
\hline 26 & .641 & 46 & .714 & .131 & .180 & .161 \\
\hline 28 & .595 & 52 & .692 & .130 & - & .321 \\
\hline 29 & .697 & 38 & .668 & .375 & .251 & - \\
\hline 34 & .525 & 39 & .632 & .329 & .146 & .140 \\
\hline 37 & .743 & 34 & .604 & .345 & .187 & - \\
\hline 38 & .656 & 50 & .567 & - & .167 & .454 \\
\hline 39 & .549 & 29 & .267 & .760 & & .216 \\
\hline 40 & .775 & 25 & .316 & .704 & .140 & - \\
\hline 41 & .731 & 22 & .250 & 671 & .236 & - \\
\hline 42 & .757 & 28 & - & .669 & & .367 \\
\hline 43 & .792 & 26 & .442 & .631 & .202 & - \\
\hline 44 & .776 & 8 & .256 & .163 & .710 & .253 \\
\hline 46 & .586 & 3 & .124 & .270 & .698 & .156 \\
\hline 47 & .744 & 7 & .361 & .121 & .689 & .311 \\
\hline 48 & .650 & 5 & .396 & - & .612 & - \\
\hline 49 & .678 & 18 & - & - & .231 & .830 \\
\hline 50 & .557 & 19 & .251 & .240 & - & 688 \\
\hline 52 & .606 & 17 & .218 & .275 & .385 & .554 \\
\hline
\end{tabular}

Table 4 above shows the communalities and factor loadings of items. The communalities ranged from .525 (Item 34) to .792 (Item 43) which were satisfactory (Costello \& Osborne, 2005). As for factor loadings, they ranged from .826 (Item 44) to .567 (Item 50) in the first factor; in the second factor from .760 (Item 29) to .631 (Item 26); in the third factor from .698 (Item 3) to .612 (Item 5) and finally in the fourth factor from .830 (Item 18) to .554 (Item 17). In the literature it is stated that factor loadings should be $\geq .450$ (Büyüköztürk, 2011), so the loadings obtained were deemed satisfactory.

Table 5. Eigenvalues and variances explained

\begin{tabular}{llll}
\hline Factor & Eigenvalue & \% of variance & Cumulative \% \\
\hline $\mathbf{1}$ & 13.098 & 48.509 & 48.509 \\
$\mathbf{2}$ & 1.834 & 6.792 & 55.302 \\
$\mathbf{3}$ & 1.651 & 6.114 & 61.415 \\
$\mathbf{4}$ & 1.111 & 4.114 & 65.530 \\
\hline
\end{tabular}

As seen in Table 5, the four factors explain $65.53 \%$ of the total variance. The total 
variance explained by the factors are satisfactory because it was nearly $2 / 3$ of the total variance (Büyüköztürk, 2011). The factor structure emerged from exploratory factor analysis was tested through confirmatory factor analysis. The next section presents findings of this analysis.

\section{Findings on confirmatory factor analysis}

In scale development studies, it is a common practice to test the factor structure that emerged out of exploratory factor analysis through confirmatory factor analysis. Confirmatory factor analysis enables researchers to test this structure on data obtained from a different sample (Whortington \& Whittaker, 2006). So, we calculated factor loadings, $t$ values and goodness of fit indices. The factor loadings ranged from .642 (Item 34 ) to .866 (Item 47) in the first factor; from .616 (Item 25) to .787 (Item 26) in the second factor; from .545 (Item 5) to .846 (Item 7) in the third factor and from .647 (Item 17) to .798 (Item 18) in the last one. According to Kline (2009) these values are satisfactory. On the other hand, all the $t$ values showing the statistical significance level of the relationship between the latent factor and the items were found to be significant at $p<.01$ level and they were greater than 2.56 (Ullman, 2013). Lastly, goodness of fit indices were examined within the context of confirmatory factor analysis. The fit indices were as follows $x^{2} / d f=2.993, C F I=.904, S R M R=.054, G F I=.821, A G F I=.787, N F I=.863$, NNFI= .894 and $R M S E A=.075$. Brown (2015) states that four indices $\left(x^{2} / d f ; C F I ; S R M R\right.$ and $R M S E A$ ) would be enough to evaluate the model fit. In this sense, the findings indicated good fit (Schermelleh-Engel, Helfried, Moosbrugger \& Müller, 2003; Sümer, 2000). In Figure 1 below, the path diagram of the scale is presented.

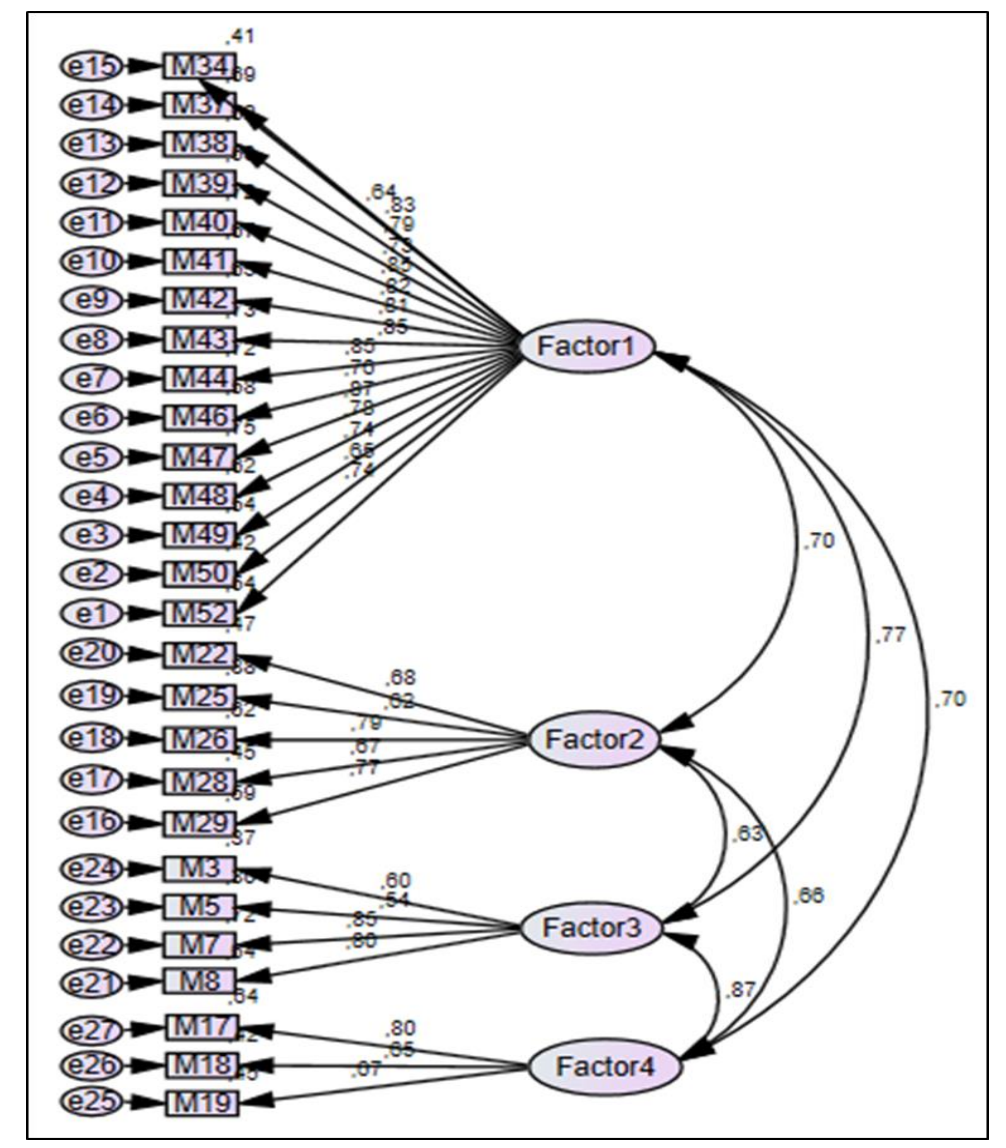

Figure 1. Path diagram 


\section{Findings on reliability and item analysis}

The reliability of scale was tested through Cronbach's Alpha coefficient both for overall scale and individual factors. Considering item statistics, difference between $27 \%$ upper-lower groups' mean scores and corrected item total correlations were calculated (Büyüköztürk, 2011). The findings on the differences between $27 \%$ upper-lower groups' mean scores are presented in Table 6 below.

Table 6. Reliability and item statistics

\begin{tabular}{|c|c|c|c|c|c|c|c|}
\hline Factor & Item no & Group & $\mathbf{n}$ & $\overline{\mathbf{x}}$ & SS & $\mathbf{t}$ & $\mathbf{p}$ \\
\hline \multirow{30}{*}{ Factor 1} & \multirow{2}{*}{34} & Lower $27 \%$ & 95 & 1.347 & .649 & \multirow{2}{*}{-14.226} & \multirow{2}{*}{.000} \\
\hline & & Upper $27 \%$ & 95 & 3.263 & 1.141 & & \\
\hline & \multirow{2}{*}{37} & Lower $27 \%$ & 95 & 1.210 & .459 & \multirow{2}{*}{-19.247} & \multirow[b]{2}{*}{.000} \\
\hline & & Upper $27 \%$ & 95 & 3.663 & 1.154 & & \\
\hline & \multirow{2}{*}{38} & Lower $27 \%$ & 95 & 1.105 & .309 & \multirow{2}{*}{-17.499} & \multirow{2}{*}{.000} \\
\hline & & Upper $27 \%$ & 95 & 3.231 & 1.143 & & \\
\hline & \multirow{2}{*}{39} & Lower $27 \%$ & 95 & 1.568 & .709 & \multirow{2}{*}{-17.974} & \multirow{2}{*}{.000} \\
\hline & & Upper $27 \%$ & 95 & 3.747 & .945 & & \\
\hline & \multirow{2}{*}{40} & Lower $27 \%$ & 95 & 1.115 & .353 & \multirow{2}{*}{-22.290} & \multirow{2}{*}{.000} \\
\hline & & Upper $27 \%$ & 95 & 3.536 & .998 & & \\
\hline & \multirow{2}{*}{41} & Lower $27 \%$ & 95 & 1.252 & .564 & \multirow{2}{*}{-22.632} & \multirow{2}{*}{.000} \\
\hline & & Upper $27 \%$ & 95 & 3.800 & .941 & & \\
\hline & 42 & Lower $27 \%$ & 95 & 1.336 & .518 & - 143 & \\
\hline & 42 & Upper $27 \%$ & 95 & 3.768 & 1.056 & -20.143 & .000 \\
\hline & 43 & Lower $27 \%$ & 95 & 1.147 & .356 & 10216 & 000 \\
\hline & 43 & Upper $27 \%$ & 95 & 3.326 & 1.046 & -19.210 & .000 \\
\hline & 44 & Lower $27 \%$ & 95 & 1.147 & .437 & & \\
\hline & 44 & Upper $27 \%$ & 95 & 3.431 & 1.048 & -19.004 & .000 \\
\hline & 46 & Lower $27 \%$ & 95 & 1.536 & .769 & -18141 & 000 \\
\hline & 40 & Upper $27 \%$ & 95 & 3.821 & .956 & -10.141 & .000 \\
\hline & 47 & Lower $27 \%$ & 95 & 1.336 & .576 & & \\
\hline & 47 & Upper $27 \%$ & 95 & 3.894 & .994 & -21.092 & .000 \\
\hline & 48 & Lower $27 \%$ & 95 & 1.263 & .488 & -15220 & 000 \\
\hline & 40 & Upper $27 \%$ & 95 & 3.115 & 1.080 & -15.229 & .000 \\
\hline & 40 & Lower $27 \%$ & 95 & 1.157 & .395 & & \\
\hline & 49 & Upper $27 \%$ & 95 & 2.705 & 1.009 & -13.918 & .000 \\
\hline & 50 & Lower $27 \%$ & 95 & 2.168 & 1.182 & -13.787 & 000 \\
\hline & 50 & Upper $27 \%$ & 95 & 4.189 & .803 & $-15.18 /$ & .000 \\
\hline & 52 & Lower $27 \%$ & 95 & 1.652 & .769 & & \\
\hline & 52 & Upper $27 \%$ & 95 & 3.715 & 1.108 & -14.915 & .000 \\
\hline & 22 & Lower $27 \%$ & 95 & 1.115 & .353 & 0514 & 000 \\
\hline & 22 & Upper $27 \%$ & 95 & 2.242 & 1.099 & -9.514 & .000 \\
\hline & 25 & Lower $27 \%$ & 95 & 1.221 & .605 & -9719 & 000 \\
\hline & 25 & Upper $27 \%$ & 95 & 2.357 & .967 & -9.119 & - \\
\hline Factor ? & & Lower $27 \%$ & 95 & 1.263 & .530 & 12764 & 000 \\
\hline Factor 2 & 26 & Upper $27 \%$ & 95 & 2.936 & 1.060 & $-13 . / 64$ & .000 \\
\hline & 28 & Lower $27 \%$ & 95 & 1.252 & .525 & 10524 & 000 \\
\hline & 28 & Upper $27 \%$ & 95 & 2.557 & 1.089 & 10.524 & .000 \\
\hline & 20 & Lower $27 \%$ & 95 & 1.115 & .353 & 12104 & 000 \\
\hline & 29 & Upper $27 \%$ & 95 & 2.400 & .972 & -12.104 & .000 \\
\hline & 3 & Lower $27 \%$ & 95 & 1.452 & .796 & -11728 & 000 \\
\hline & $\boldsymbol{3}$ & Upper $27 \%$ & 95 & 3.178 & 1.194 & $-11 . / 28$ & .000 \\
\hline & & Lower $27 \%$ & 95 & 1.863 & 1.136 & & \\
\hline Factor 3 & 5 & Upper $27 \%$ & 95 & 3.778 & .958 & -12.566 & .000 \\
\hline Factor 3 & & Lower $27 \%$ & 95 & 1.442 & .680 & -15415 & 000 \\
\hline & 7 & Upper $27 \%$ & 95 & 3.431 & 1.058 & -15.415 & .000 \\
\hline & & Lower $27 \%$ & 95 & 1.368 & .566 & & \\
\hline & 8 & Upper $27 \%$ & 95 & 3.094 & 1.073 & $-13.8 / 4$ & .000 \\
\hline & 17 & Lower $27 \%$ & 95 & 1.273 & .493 & -12965 & 000 \\
\hline Factor 4 & 17 & Upper $27 \%$ & 95 & 2.810 & 1,045 & -12.905 & .000 \\
\hline & 18 & Lower $27 \%$ & 95 & 1.863 & .996 & -8.807 & .000 \\
\hline
\end{tabular}




\begin{tabular}{|c|c|c|c|c|c|c|c|}
\hline & 19 & $\begin{array}{l}\text { Upper } 27 \% \\
\text { Lower } 27 \% \\
\text { Upper } 27 \% \\
\end{array}$ & $\begin{array}{l}95 \\
95 \\
95 \\
\end{array}$ & $\begin{array}{l}3.210 \\
1.568 \\
3.336 \\
\end{array}$ & $\begin{array}{l}1.110 \\
.834 \\
1.154 \\
\end{array}$ & -12.107 & .000 \\
\hline Total & & $\begin{array}{l}\text { Lower } 27 \% \\
\text { Upper } 27 \%\end{array}$ & $\begin{array}{l}95 \\
95\end{array}$ & $\begin{array}{l}1.375 \\
3.279\end{array}$ & $\begin{array}{l}.207 \\
.423\end{array}$ & -39.427 & .000 \\
\hline
\end{tabular}

Table 6 shows the differences between lower and upper $27 \%$ groups' means scores. The findings indicated that the differences were statistically significant for all items and for overall scale at $p=.000$ level. So, it can be argued that the items distinguish individuals well (Büyüköztürk, 2011).

Table 7. Corrected item total correlations

\begin{tabular}{llllll}
\hline Factor & Item no & CITC & Factor & Item no & CITC \\
\hline & $\mathbf{3 4}$ & .622 & & $\mathbf{2 2}$ & .639 \\
& $\mathbf{3 7}$ & .810 & & $\mathbf{2 5}$ & .564 \\
& $\mathbf{3 8}$ & .773 & Factor 2 & $\mathbf{2 6}$ & .686 \\
& $\mathbf{3 9}$ & .715 & & $\mathbf{2 8}$ & .585 \\
& $\mathbf{4 0}$ & .826 & & $\mathbf{2 9}$ & .686 \\
& $\mathbf{4 1}$ & .806 & & $\mathbf{3}$ & .540 \\
& $\mathbf{4 2}$ & .790 & Factor 3 & $\mathbf{5}$ & .488 \\
& $\mathbf{4 3}$ & .832 & & $\mathbf{7}$ & .698 \\
& $\mathbf{4 4}$ & .828 & & $\mathbf{8}$ & .623 \\
& $\mathbf{4 6}$ & .847 & & $\mathbf{1 7}$ & .608 \\
& $\mathbf{4 7}$ & .763 & & $\mathbf{1 8}$ & .565 \\
& $\mathbf{4 8}$ & .721 & & $\mathbf{1 9}$ & .546 \\
& $\mathbf{4 9}$ & .637 & & & \\
\hline
\end{tabular}

As for corrected item total correlations, they ranged from .622 (Item 34) to .848 (Item 47) in the first factor; from .686 (Items 26-29) to .564 (Item 25) in the second factor; from .488 (Item 5) to .698 (Item 7) in the third factor and from .546 (Item 19) to .608 (Item 17). All the values are >.300 which is an indication of internal consistency (Field, 2009).

Table 8. Correlations among factors

\begin{tabular}{lllll}
\hline Factor & Factor1 & Factor2 & Factor3 & Factor4 \\
\hline Factor 1 & 1 & & & \\
Factor 2 & $.621^{* *}$ & 1 & & \\
Factor 3 & $.731^{* *}$ & $.554^{* *}$ & 1 & 1 \\
Factor 4 & $.598^{* *}$ & $.505^{* *}$ & $.658^{* *}$ & 1 \\
\hline
\end{tabular}

Table 8 shows the correlations among the factors. Correlation coefficients between $r=.000-.300$ are considered as low; $r=.300-700$ moderate and $r=.700-1.000$ high (Büyüköztürk, 2011). Considering these cutoff values, there are moderate and high level statistically significant positive correlations among factors. They range from $r=.505$ to $r=.731$ showing that factors are related and compatible. Lastly, Cronbach's Alpha and test-retest reliability coefficients were calculated. The findings are presented below.

Table 9. Reliability coefficients

\begin{tabular}{lll}
\hline Factors & Cronbach's Alpha & Test-retest \\
\hline Factor 1 & .958 & $.945^{* *}$ \\
Factor 2 & .831 & $.808^{* *}$ \\
Factor 3 & .776 & $.782^{* *}$ \\
Factor 4 & .743 & $.622^{* *}$ \\
Overall scale & .959 & $.920^{* *}$ \\
\hline
\end{tabular}

** $p<.01$ 
As can be witnessed in Table 9, Cronbach's Alpha coefficients range from .743 to .959 which are satisfactory considering the cutoff values in literature (Lester, Inman \& Bishop, 2014). These findings confirm the internal consistency of the scale. In terms of test-retest reliability, the scale was administered to a group of 25 teachers with a two-weeks interval and the correlation between two measurements were calculated through Spearman Brown correlation coefficients (Salkind, 2010). The findings showed that there are statistically significant positive high-level correlations both based on the factors and overall scale. In this vein, arguably the scale has stability.

In the last step of this scale development study, the factors emerged were named. Table 10 below shows the names of factors and items loading on them.

Table 10. Naming the factors and items

\begin{tabular}{lll}
\hline Factors & Number of items & Items and sample item \\
\hline Unable to subordinate self & 15 & $\begin{array}{l}34,37,38,39,40,41,42,43,44,46,47,48,49,50,52 \\
\text { My school principal wants to be conferred } \\
\text { with every decision taken at school. }\end{array}$ \\
& 5 & $\begin{array}{l}22,25,26,28,29 \\
\text { My school principal is too busy to talk to his } \\
\text { subordinates. }\end{array}$ \\
Time manipulation & $3,5,7,8$ \\
Excessive control over & 4 & $\begin{array}{l}\text { My school principal is obsessed with trivial } \\
\text { details. } \\
\text { methodology }\end{array}$ \\
Excessive reporting & 3 & $\begin{array}{l}\text { My school principal often asks for status } \\
\text { report. }\end{array}$ \\
& &
\end{tabular}

\section{Discussion and Conclusion}

The aim of this study was to develop a valid and reliable scale to measure school principals' micromanagement behaviors. To this end, the steps suggested by DeVellis (2017) were followed. Firstly, indicators of micromanagement were determined through a comprehensive literature review. These indicators have been turned into scale items and evaluated by a panel of experts. This procedure yielded an item pool of 52 items which were adapted to context of school.

Exploratory factor analysis was the second step to reveal the factor structure of the scale. In this step, 25 items were discarded from the pool. The structure in which the remaining 27 items loading on four factors showed adequate psychometric properties. The initial item pool had 52 items and nearly half of them were retained in the scale which may bring the content validity issue into question. Hinkin, Tracey \& Enz (1997) argue that there are no specific rules about the number of items to be retained and it should be anticipated that one half of the items could be removed which was almost the case in this study. On the other hand, Raubenheimer (2004) states that there should be at least 3 items for each factor as long as the reliability and validity criteria are met. MacCallum, Widaman, Zhang \& Hong (1999) give some clues about the number of factors and items for ensuring content validity, as well. They suggest that researchers consider communalities while deciding the number of factors. They emphasize that particularly in the early stages of factor analytic research in a specific domain, an investigator may not be able to guess the number of factors in a scale. If results show a relatively small number of factor and moderate to high communalities, it can be asserted that obtained factors represent a close match to population of factors. Based on this, it would be fair to state that the number of 
factors and items on them can be deemed satisfactory considering the content validity issue. However, this is a pioneering study dealing with micromanagement in terms of schools. So, it stands as a reference to further studies which can add new factors or items to the existing scale and improve it. The total variance explained was $65.53 \%$. Hinkin et.al. (1997) noted that a minimum $60 \%$ might serve as acceptable for the total variance explained. On the other hand, the factors were named as "unable to subordinate self", "time manipulation", "excessive control over methodology" and "excessive reporting". There were 15 items in "unable to subordinate self"; 5 items in "time manipulation"; 4 items in "excessive control over methodology" and 3 items in "excessive reporting". Early studies on micromanagement are mostly in the form of review, which do not measure the concept empirically (Chambers, 2004; Cleary et.al., 2015; Collins \& Collins, 2002; Hills, 2017; Serrat, 2010; Taylor, 2016; White, 2010; Wright, 2000). Based on these early studies, there have been efforts to develop valid and reliable tools to measure it (Hume, 2019; Lewis, 2014; Li \& Khalid, 2015; Sulphey \& Upadhyay, 2019). In these studies there is not an agreement on the dimensions of micromanagement. For example, the scale developed by Hume (2019) has a unidimensional construct, while a four-factor structure was put forward by Sulhey \& Upadhyay (2019) just like in the current study. However, the latter one does not provide the name of factors in the article. As for Li \& Khalid (2015) and Lewis (2014), they use a framework based on Chambers (2004). According to this, the dimensions of micromanagement are excessive control over methodology, excessive reporting and updates, control and manipulation of time, failure to subordinate self, excessive approval requirement and exercise of raw power/imposing their will. While naming the factors, it was observed that the items under the factors were consistent with four of these conceptualizations and they were named accordingly.

The factor structure emerged from exploratory factor analysis was tested through confirmatory factor analysis on data obtained from a different sample. In this context, factor loadings, $t$ and goodness of fit indices were calculated. The findings confirmed the four-factor structure of the scale (Brown, 2015; Kline, 2009; Schermelleh-Engel, Helfried, Moosbrugger \& Müller, 2003; Sümer, 2000; Ullman, 2013).

Reliability analysis of the scale was conducted on data set was which used for confirmatory factor analysis. In this sense, Cronbach's Alpha coefficient, significance of the differences between the upper and lower $27 \%$ groups' means scores and corrected item total correlations were calculated. Additionally, the relationships among factors of the scale were examined. The findings showed that the scale had high internal consistency and items distinguished individuals well (Büyüköztürk, 2011; Field, 2009; Lester, Inman $\&$ Bishop, 2014). Test-retest reliability also provided support for the stability of the scale.

In conclusion, the scale developed in this study has adequate psychometric properties. It is a valid and reliable measure. It can be employed to measure levels of principals' micromanagement behaviors.

This is a pioneering study that addresses micromanagement in the context of educational organizations. The scale can be applied to different and larger samples. In the current study, teachers evaluated school principals. Further studies can be carried out as selfevaluation of school principals or evaluation of school principals by different stakeholders (assistant principal, officer or assistant staff). To this end, existing scale items can be adapted. Additionally, the scale can be used to associate micromanagement with variables such as school culture, organizational effectiveness, psychological climate, 
organizational commitment, job satisfaction, motivation, performance, turnover intention etc. The micromanagement behavior of school principals can be analyzed more in depth by conducting qualitative and mixed method studies.

Although it provides some important implications, this scale development study has some limitations. Firstly, it employed a deductive method in item generation which means that items were prepared based on existing scales and literature. Secondly, there is not a reversely scored item in the scale. The final construct of the scale involves four dimensions of micromanagement. Lastly, the validity and reliability of the scale is limited to statistical analyses conducted within this current study.

\section{References}

Alizor, J. O. (2013). Leadership: Understanding theory, style, and practice. Bloomington: WestBow Press.

Balc1, A. (2019). Explaining dictionary of educational administration concepts. Ankara: Pegem Academy Publishing.

Bergstrom, P. \& Raknes, L. P. (2016). Prosperous micromanagement: A qualitative study of leadership behaviour in high performing retail stores (Unpublished master's thesis). BI Norwegian Business School, Oslo, Norway.

Bielaszka-DuVernay, C. (2008). Micromanage at your peril. Harvard Business Review, February. Retrieved from https://hbr.org/2008/02/micromanage-at-yourperil.html on 23.04.2020.

Brown, T. A. (2015). Confirmatory factor analysis for applied research. New York: The Guilford Press.

Bursalığgl, Z. (2010). New structure and behaviors in school administration. Ankara: Pegem Academy Publishing.

Büyüköztürk, Ş. (2011). Manual of data analysis for social sciences. Ankara: Pegem Academy Publishing.

Chambers, H. E. (2004). My way or the highway: The micromanagement survival guide. San Francisco: Berrett-Koehler Publishers.

Clearly, M., Hungerford, C., Lopez, V. \& Cutcliffe, J. R. (2015). Towards effective management in psychiatric-mental health nursing: The dangers and consequences of micromanagement. Issues in Mental Health Nursing, 36(6), 424-429. http://dx.doi.org/10.3109/01612840.2014.968694

Collins, S. K. \& Collins, K. S. (2002). Micromanagement: A costly management style. Radiology Management, 24(6), 32-35.

Costello, A. B. \& Osborne, J. W. (2005). Best practices in exploratory factor analysis: Four recommendations for getting the most from your analysis. Practical Assessment, Research \& Evaluation, 10(7), 1-9.

Delgado, O., Strauss, E. M. \& Ortega, M. A. (2015). Micromanagement: When to avoid it and how to use it effectively. American Journal of Health-System Pharmacy, 72(May), 772-776. http://dx.doi.org/102146/ajhp140125

DeVellis, R. F. (2017). Scale development theory and applications. Thousand Oaks, CA: Sage Publications.

Field, A. (2009). Discovering statistics using SPSS. Los Angeles: Sage Publications.

Fracaro, K. E. (2007). The consequences of micromanaging. Journal of Contract Management, July 4-8.

Hair, J. F., Black, W. C., Babin, B. J. \& Anderson, R. E. (2014). Multivariate data analysis. Essex: Pearson Education. 
Hills, L. (2017). Are you micromanaging your team? How to find out and how to stop. The Journal of Medical Practice Management, 32(6), 394-398.

Hinkin, T. R., Tracey, J. B. \& Enz, C. A. (1997). Scale construction: Developing reliable and valid measurement instruments. Journal of Hospitality \& Tourism Research, 21(1), 100-120. https://doi.org/10.1177/109634809702100108

Huck, S. W. (2012). Reading statistics and research. Boston: Pearson Education.

Hume, H. (2019). Micromanagement scale: Development and validation (Unpublished master's thesis). Illinois State University, the USA.

Jazzar, M. (2005). Tales of micromanagement, part 1. American School Board Journal, 192(8), 31.

Kaskey, R. R. (2015). Factors contributing to the retention and turnover of school principals in Pennsylvania (Unpublished doctoral dissertation). Widener University, Pennsylvania, the U.S.A.

Kline, R. B. (2009). Principles and practice of structural equation modeling. New York: The Guilford Press.

Küçükçayır, G. A. \& Güçlü, N. (2017). The organisational structure of schools and an organisational problem: Mobbing: The 12. International Congress of Educational Administration, at Klzllcahamam,

Lampton, J. A. (2002). An analysis reasons for governing board micromanagement of administrative affairs in public community colleges (Unpublished doctoral dissertation). Saint Louis University, Missouri, the U.S.A.

Lester, P. E., Inman, D. \& Bishop, L. (2014). Handbook of tests and measurement in education and the social sciences. Lanham: Rowman \& Littlefield.

Lewis, J. O. (2014). Why micromanage? Leaders in quality should be the example (Unpublished master's thesis). California State University Dominguez Hills, California, the U.S.A.

Li, J. \& Khalid U. (2015) Micromanaging behaviour and engineering management: A quantitative study of micromanaging behaviour of engineering managers (Unpublished master's thesis). Lund University, the Sweden.

MacCallum, R. C., Widaman, K. F., Zhang, S. \& Hong, S. (1999). Sample size in factor analysis. Psychological Methods, 4(1), 84-99. http://dx.doi.org/10.1037/1082989X.4.1.84

Meyers, E. F. \& Richardson, M. D. (2014). School board micromanagement: Apprehension for superintendents. The Journal of Teaching, Learning, and Research in Educational Leadership, 4(3).

Ullman, J. B. (2013). Structural equation modeling. In (Eds.) B. G. Tabachnick, \& L. S. Fidell, Using multivariate statistics (pp. 681-785). Boston: Pearson.

Pallant, J. (2007). SPSS survival manual a step by step guide to data analysis using SPSS for windows. Berkshire: McGraw Hill.

Plemons, R. (2014). Staff perceptions of work-environment factors affecting morale in Southeastern registrars offices (Unpublished doctoral dissertation). Western Kentucky University, Kentucky, the U.S.A.

Prosper, P. (2012). The effects of network-centric warfare on micromanagement, centralized control, and decentralized execution in combat (Unpublished doctoral dissertation). University of Phoenix, the U.S.A.

Saenz, C. S. (2005). School governance: A study of the effect of micromanagement on decision-making processes of school superintendents (Unpublished doctoral dissertation). Capella University, Minnesota, the U.S.A.

Salkind, N. J. (2010). Encyclopedia of research design (Vols. 1-0). Thousand Oaks, CA: SAGE Publications, Inc. doi: 10.4135/9781412961288 
Schuster, E. N. (2019). Who's the boss? The role of management style and communication in the workplace. IU Southeast Student Conference, April 18-19, 2019.

Schermelleh-Engel, K., Moosbrugger, H. \& Müller, H. (2003). Evaluating the fit of structural equation models: Tests of significance and descriptive goodness-of-fit measures. Methods of Psychological Research Online, 8(2), 23-74.

Scott, D. A. (2010). The influence of principal leadership characteristics and actions on teacher retention: Teachers' lived experience (Unpublished doctoral dissertation). University of Phoenix, Arizona, the U.S.A.

Serrat, O. (2010). The travails of micromanagement. Washington, D.C.: Asian Development Bank.

Sidhu, A. S. (2012). Micromanagement: A project management tool in crisis. International Journal of Economics and Management Sciences, 1(12), 71-77.

Sledge, J. C. (2016). Motivation and retention of generation y employees in the workplace (Unpublished doctoral dissertation). Argosy University, Phoenix, the U.S.A.

Sulphey, M. M. \& Upadhyay, Y. K. (2019). Construction and validation of micromanagement questionnaire. Int. J. Environment, Workplace and Employment 5(3), 193-205.

Sümer, N. (2000). Structural equation modelling: Basic concepts and applications. Turkish Psychological Review, 3(6), 49-74.

Şencan, H. (2005). Validity and reliability in social and behavioral measurements. Ankara: Seçkin.

White, R. D. (2010). The micromanagement disease: Symptoms, diagnosis, and cure. Public Personnel Management, 39(1), 71-76.

Wright, R. F. (2000). Strategies for avoiding the micromanagement trap. Management Decision, 38(5), 362-364. http://dx.doi.org/10.1108/00251740010340544

Worthington, R. L. \& Whittaker, T. A. (2006). Scale development research: A content analysis and recommendations for best practices. The Counseling Psychologist, 34(6), 806-838. http://dx.doi.org/10.1177/0011000006288127

Villarreal, L. P. (2003). An analysis of ethics in Texas school governance (Unpublished doctoral dissertation). Texas A\&M University, Kingsville, the U.S.A.

Y1lmaz, A. İ. \& Beycioğlu, K. (2017). Teachers' perceptions regarding bureaucratic structures in schools. Anadolu University Journal of Education Faculty, 1(2), 123. 